\title{
Autoeficácia no uso do computador em situações de aprendizagem: uma análise da literatura internacional
}

Self-efficacy in computer use in learning situations: a review of the international literature La autoeficacia en el uso del computador en situaciones de aprendizaje: un análisis de la literatura internacional

» Vanessa da Fonseca GUIMARÃES ${ }^{1}$ (Universidade de Brasília)

» Gardênia da Silva ABBAD² (Universidade de Brasília)

ResumO Este trabalho apresenta uma revisão da literatura sobre a autoeficácia no uso do computador (AEC) e tem como objetivos analisar e comparar definições e escalas adotadas pelos autores e examinar os principais resultados dessas pesquisas. Autoeficácia no uso do computador refere-se à crença que um indivíduo tem sobre a sua própria capacidade de usar com sucesso o computador e seus recursos. Esse conceito é importante em estudos sobre educação e treinamento, pois tem se mostrado correlacionado positivamente com aprendizagem, transferência de treinamento, atitudes e nível de participação de estudantes e trabalhadores em cursos presenciais e a distância mediados por computador. A revisão da literatura abrangeu textos científicos publicados entre 1998 e 2011 em revistas com corpo editorial e revisão por pares, encontradas no PsycINFO, Web of Science, BVS Psicologia ULAPSI Brasil e Scielo. Foram analisados 30 artigos que aplicaram escalas de avaliação de AEC. Os estudos mostraram que: as escalas avaliam apenas força, uma das três dimensões de autoeficácia propostas por Bandura (1986); não há distinção clara entre autoeficácia específica e geral; AEC está correlacionada positivamente com importantes resultados como aprendizagem e atitudes de participantes de cursos que adotam computadores no ensino. Ao final do artigo é proposta uma agenda de pesquisa para aprimorar medidas de AEC e investigar a relação dessa variável com aprendizagem, ansiedade ou estresse vivenciado por aprendizes, atitudes de aceitação ou rejeição de tecnologias no uso de computadores e novas tecnologias de informação e comunicação (NTICs). Palavras-chave:

Autoeficácia no uso do computador; treinamento; aprendizagem.

Abstract This study presents a review of the literature on "Computer Self-Efficacy" (CSE) and has the objective to: analyze and compare definitions and scales that have been adopted by the authors and analyze the main results of these studies. Computer Self-Efficacy refers to the belief that an individual has about his/her own ability to use a computer and its resources successfully. CSE is important in studies on education and training since it has proven to be positively correlated with learning, transfer of training, attitudes, and levels of participation of students and workers in face-to-face as well as distance courses taught through the use of computers. The review of the literature included articles published between 1998 and 2011 in peer reviewed journals found in PsycINFO, Web of Science, BVS Psicologia ULAPSI Brasil, and Scielo. Thirty articles that use CSE scales were analyzed. The studies indicate that: the scales only evaluate strength, one of the three dimensions of self-efficacy proposed by Bandura (1986); there is no clear distinction between specific and general self-efficacy; CSE is positively correlated with important results such as learning and participants' attitudes in courses that use computers for teaching. At the end of the article, an agenda for future research is proposed to improve measures of CSE and better investigate the relationship of this variable with learning, anxiety, and stress experienced by learners, and to investigate attitudes of acceptance or rejection of technologies with the use of computers and NICTs (New Information and Communication Technologies).

Keywords:

Computer self-efficacy; training; learning.

1 Vanessa da Fonseca Guimarães, mestre em Psicologia Aplicada pela Universidade Federal de Uberlândia, doutora em Psicologia Social e do Trabalho pela Universidade de Brasília. E-mail: vanessa1212@gmail.com

2 Gardênia da Silva Abbad, doutora em Psicologia Social e do Trabalho pela Universidade de Brasília, professora adjunta no Departamento de Psicologia Social e do Trabalho da Universidade de Brasília. E-mail: gardenia.abbad@gmail.com 
El presente trabajo presenta una revisión de la literatura sobre la "autoeficacia en el uso del computador”(AEC). Tiene como objetivos: analizar y comparar las definiciones y las escalas adoptadas por los autores y analizar los principales resultados de estas investigaciones. La auto-eficacia en el uso del computador se refiere a la creencia que una persona tiene acerca de su propia capacidad en utilizar correctamente el computador y sus recursos. AEC es importante en los estudios sobre educación y formación, dado que se ha demostrado una correlación positiva con el aprendizaje, la transferencia del entrenamiento, las actitudes y el nivel de participación de los estudiantes y de los trabajadores en cursos presenciales y a distancia, mediada por ordenador. La revisión de la literatura incluyó textos científicos publicados entre 1998 y 2011 en revistas con comisión de editores y de revisión por pares, encontradas en las bases PsycINFO, Web of Science, Psicología BVS ULAPSI Brasil, Scielo. Se analizaron 30 artículos que aplicaron escalas de evaluación de AEC. Los estudios han demostrado que: las escalas evalúan apenas la fuerza, una de las tres dimensiones de la auto-eficácia propuestas por Bandura (1986); no hay una distinción clara entre la autoeficacia especifica y general; la AEC se correlaciona positivamente con resultados importantes como el aprendizaje y las actitudes de los participantes de cursos que adoptan computadores en la enseñanza. Al final del artículo se propone una agenda de investigación para mejorar las medidas de AEC e investigar más profundamente la relación de esta variable con el aprendizaje, la ansiedad o el estrés experimentado por los alumnos, las actitudes de aceptación o rechazo de las tecnologías en el uso de las computadoras y las NTIC.

Palabras-claves:

Autoeficacia en el empleo del computador; entrenamiento; aprendizaje.

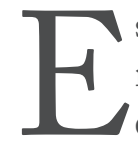

ste artigo apresenta uma revisão da literatura internacional de estudos sobre a autoeficácia no uso do computador (AEC) que adotaram medidas psicométricas na avaliação de eventos educacionais e de treinamentos corporativos. Compeau e Higgins (1995) definem AEC como a autoavaliação ou o julgamento que uma pessoa faz acerca da sua própria capacidade de utilizar com sucesso um computador e seus recursos. Essa definição, adotada em diversos estudos analisados neste artigo, foi elaborada por esses autores conforme a teoria de Bandura (1986).

A avaliação do efeito da autoeficácia no uso do computador em situações educacionais é importante devido ao crescente investimento das organizações e das instituições de ensino em formação e capacitação profissional por meio de cursos mediados por computador e por novas tecnologias de informação e comunicação (NTICs). A democratização da educação, mediante o uso das NTICs em cursos presenciais, a distância e híbridos, a necessidade de aprendizado constante de novas e complexas competências profissionais e o aumento de cursos on-line fizeram emergir uma necessidade e um maior interesse em investigar quais fatores individuais, de contexto e organizacionais favorecem ou prejudicam os resultados de atividades instrucionais ou educacionais com tais características.

Relatos de pesquisas em contextos educacionais apontam relações positivas entre AEC e importantes processos individuais e resultados, como participação, atitudes e desempenho em cursos mediados por NTICs. Participantes com maior AEC e que fizeram cursos mediados pelo computador apresentaram maior participação e atitudes mais positivas do que os demais estudantes (Torkzadeh, Pflughoeft, \& Hall, 1999; Eastin, \& LaRose, 2000), percepções mais favoráveis sobre conforto no uso de computadores (Barbeite \& Weiss, 2004), mais disposição para usar programas disponibilizados pelo computador (Brinkerhoff, 2006; Hsu, Wang, \& Chiu, 2009) e melhor rendimento dos aprendizes em cursos e-learning (Papasratorn \& Wangpipatwong, 2006).

A revisão da literatura apresentada demonstra uma relativa escassez de artigos nacionais e internacionais sobre medidas de autoeficácia no uso do computador, especialmente em estudos sobre treinamentos corporativos. Restam, em função disso, muitas lacunas e questões de pesquisa, sendo que algumas delas motivaram este estudo. Entre elas estão as seguintes: (1) Há algum referencial teórico predominante nas pesquisas sobre AEC? (2) Quais são as definições adotadas na construção de escalas de AEC? (3) Quais contextos de pesquisa (educacionais ou de treinamento corporativo) e amostras de participantes são mais estudados? (4) Em que se assemelham as escalas de medida adotadas nos estudos? (5) Os principais achados das pesquisas mostram quais relações (positivas diretas ou indiretas) de AEC com quais resultados de aprendizagem? (6) Quais são as principais lacunas nas pesquisas sobre AEC?

Este trabalho revisa a produção de conhecimentos sobre a AEC com o intuito de responder a essas questões, considerando-se a relevância do tema, as evidências de relacionamento positivo entre autoeficácia e importantes resultados de aprendizagem em contextos educacionais e de treinamentos corporativos e a relativa escassez 
de estudos sistemáticos que analisem esses relacionamentos em diferentes contextos. Com o objetivo de encontrar respostas a essas questões, este trabalho buscou: (1) identificar e analisar estudos que investigam AEC em diferentes situações de aprendizagem; (2) analisar definições do construto; (3) descrever instrumentos de medida; e (4) apresentar os principais resultados e lacunas nas pesquisas. A seguir são apresentados os principais referenciais teóricos e definições de autoeficácia adotados pelos pesquisadores da área de Treinamento, Desenvolvimento e Educação (TD\&E).

\section{Autoeficácia segundo a Psicologia Social}

A Psicologia Social busca compreender, por meio de suas teorias, o comportamento do indivíduo e suas formas de se relacionar com o meio. A Psicologia Social Cognitiva investiga porque os indivíduos apresentam certos tipos de comportamentos em diferentes situações. Nesse contexto, construtos autorreferentes têm sido muito utilizados, pois são considerados adequados à investigação desses comportamentos ou atitudes.

Um construto de autoavaliação comumente estudado é a autoeficácia, traço pessoal facilmente associado a várias características desejáveis no mundo moderno, como motivação para aprender ou persistência em prol de um objetivo ou desempenho profissional (Brinkerhoff, 2006; Colquitt, LePine, \& Noe, 2000; Salanova, Grau, Cifre, \& Llorens, 2000). A análise da autoeficácia de um indivíduo pode prover ferramentas de orientação e autoconhecimento importantes, uma vez que a percepção de autoeficácia tem relações positivas com o sucesso do indivíduo em atividades específicas, indicando que "autoavaliações de capacidades são determinantes dos desempenhos gerados adiante" (Meneses \& Abbad, 2012, p. 191).

Albert Bandura, psicólogo canadense, foi pioneiro na definição do conceito de autoeficácia e proponente de uma "Teoria de Aprendizagem Social". Essa teoria sugere que a aprendizagem acontece por modelação comportamental, de modo que uma importante maneira de aprender novos comportamentos e atitudes é por meio da observação do comportamento de outra pessoa, grupo ou objeto social. A autoeficácia possibilita ao indivíduo moldar a percepção sobre suas próprias capacidades de realizar com sucesso (ou não) uma atividade. Conforme Bandura (1986), a percepção de autoeficácia é definida como as crenças das pessoas sobre suas próprias capacidades de alcançar níveis de desempenho que exercem influência sobre os eventos subsequentes que afetam suas vidas. De acordo com essa teoria, o grau de autoeficácia de um indivíduo sobre certa atividade ou situação pode influenciar os sentimentos, os pensamentos, os tipos de comportamentos ou o grau de motivação que uma pessoa possui e demonstra a respeito dessa atividade ou situação.

Os estudos sobre aprendizagem social progrediram muito quando, em 1986, Albert Bandura lançou o livro Social Foundations of Thought and Action: a social cognitive theory, em que propôs uma expansão dessa teoria por meio de uma investigação mais abrangente da motivação e da ação humana, analisando o papel da cognição, de experiências vicárias e de características autorreguladoras em processos psicossociais de aprendizagem, de comportamentos e de interação. Social Cognitive Theory (SCT) é a expressão em inglês de Teoria Social Cognitiva (TSC) proposta por Bandura (1986), que defende um ponto de vista cognitivo e interacionista na análise do comportamento individual, que tem sido amplamente utilizado em situações de aprendizagem, de promoção da saúde, de condicionamento físico e de desenvolvimento ocupacional (Kuo \& Hsu, 2001). Explicando um pouco mais sobre a TSC, Bandura (1986) afirma que aspectos pessoais internos (como os pensamentos, as emoções e os afetos) e fatores externos ou ambientais (como as normas sociais, o incentivo dos colegas e o comportamento observável) funcionam como determinantes do comportamento, capazes de se influenciarem e interagirem mutuamente.

Em um artigo mais recente, Bandura (2005) esclarece que o conceito de autoeficácia deve ser diferenciado de outros construtos autorreferentes, como a autoestima, o locus de controle e as expectativas de resultados. Conforme o autor:

Percepção de "eficácia" é o julgamento sobre um recurso, "autoestima” é um juízo de autovalor. [...] "Locus de controle" está relacionado com atribuição de causas, com a crença sobre o desfecho contingencial se os resultados são determinados por suas ações ou por forças externas de seu controle. [...] Por exemplo, os 
alunos podem acreditar que altos graus acadêmicos são inteiramente dependentes do seu desempenho (locus de controle elevado), mas se sentem desanimados porque acreditam que não têm a eficácia para produzilos. Outra distinção importante diz respeito à "expectativa de resultados" de desempenho. Percepção de autoeficácia é um julgamento da capacidade de executar certos tipos de desempenhos; "expectativas de resultados" são julgamentos sobre os resultados que possam fluir de tais desempenhos. (Bandura, 2005, p. 309)

Bandura (1986) afirma que a autoeficácia é um construto dinâmico, que muda à medida que novas informações e experiências são adquiridas pelo indivíduo. Propõe quatro fontes de informação que podem afetar o grau de autoeficácia percebido pelo indivíduo. A primeira relaciona-se à experiência pessoal do sujeito e afirma que a percepção de uma pessoa sobre suas capacidades de realizar uma atividade tende a melhorar se suas experiências anteriores lhe proporcionarem informações positivas sobre as competências similares. Bandura (1994) afirma que essa fonte é a mais eficaz em influenciar positiva ou negativamente o grau de autoeficácia percebido pelo sujeito. A segunda fonte, chamada observação vicária, relaciona-se à possibilidade de o indivíduo observar outras pessoas vivenciando situações de sucesso ou fracasso. Conforme Bandura (1994), ao observar pessoas semelhantes a si mesmo obtendo sucesso mediante esforço pessoal, aumenta a crença dos observadores de que eles também possuem a capacidade de dominar suas habilidades necessárias para obter sucesso naquela situação. $\mathrm{O}$ inverso também se mostra verdadeiro, segundo o autor. Para ele, quanto maior a semelhança assumida entre o observador e a sua referência, mais persuasivos são os modelos de sucessos e de fracassos. A terceira fonte de influência da autoeficácia sobre o indivíduo, a persuasão verbal, sugere que uma pessoa pode influenciar o grau de autoeficácia da outra a partir de informações verbais sobre a tarefa e a capacidade do sujeito em realizar a tarefa.

De acordo com Bandura (1994), as pessoas que são persuadidas verbalmente a acreditar que possuem capacidade de realizar as atividades com sucesso são suscetíveis a mobilizar um maior esforço e mantê-lo do que se abrigarem em dúvidas e se debruçarem sobre deficiências pessoais quando surgem problemas. A quarta e última fonte de influência da autoeficácia apresenta-se com um foco emocional. Nessa fonte de influência, os indivíduos têm mais possibilidade de desenvolver expectativas de sucesso se não revelarem uma alta ansiedade referente a um determinado objeto social ou situação. Assim como propõe Bandura (1994), isso ocorre ao reduzir as reações das pessoas ao estresse e ao alterar uma interpretação negativa sobre o estado emocional ou físico do sujeito.

Bandura (1986) ainda define autoeficácia como um construto multidimensional, composto por três atributos que se inter-relacionam: a magnitude, associada ao nível de dificuldade de tarefas específicas que as pessoas acreditam que podem realizar; a força, ou nível de confiança (ou convicção), apresentado pelo indivíduo sobre as próprias capacidades de executar determinadas tarefas; e a generalização, a expectativa que o indivíduo possui de poder generalizar suas capacidades, aplicando-as com êxito em situações similares.

Junto a essa proposta de aprofundar os aspectos constituintes da autoeficácia, duas premissas merecem destaque na proposição de Bandura (1986): 1) a autoeficácia é uma importante variável preditiva do desempenho de tarefas; e 2) todas as definições do construto referem-se ao quanto uma pessoa se percebe capaz de realizar com sucesso uma tarefa específica (Marakas, Mun, \& Johnson, 1998). Ciente da riqueza teórica do conceito de autoeficácia, e diante das inúmeras possibilidades de aplicação do conhecimento no âmbito educacional e corporativo, a seção seguinte detalhará os procedimentos e os resultados relacionados à revisão da literatura realizada sobre medidas de AEC na área de Treinamento, Desenvolvimento e Educação (TD\&E).

\section{Referenciais teóricos sobre autoeficácia no uso de computadores}

Goldstein (1991) foi pioneiro ao divulgar uma definição de autoeficácia mais ligada à área de Treinamento, Desenvolvimento e Educação. O autor classifica autoeficácia como um aspecto motivacional, capaz de influenciar resultados imediatos de treinamentos, como a aprendizagem. Em sua pesquisa, Goldstein (1991) argumenta que aprendizes que concluíram um treinamento e foram aprovados nas avaliações de aprendizagem, e que perceberam esse feedback como válido, apresentaram níveis elevados de autoeficácia, uma vez que se sentiram capazes de realizar com sucesso a tarefa para a qual foram treinados.

Como observado, a autoeficácia assume posição expressiva na determinação de eficácia de treinamentos, especialmente no que concerne à aplicação das competências ensinadas no trabalho. Assim, essa revisão 
buscou uma análise mais específica da autoeficácia, associando-a ao uso de computadores em ambientes de aprendizagem.

Entre os autores que estudaram autoeficácia no uso de computadores, Compeau e Higgins (1995) a definem como a crença de um indivíduo quanto à sua própria capacidade de manipular os softwares e as tarefas inerentes ao manuseio do computador. Refere-se à autopercepção do indivíduo sobre a própria capacidade para organizar e implementar ações necessárias ao desempenho desejável, a fim de ter sucesso nessas tarefas específicas. Segundo os autores:

Autoeficácia no uso do computador refere-se ao julgamento de uma pessoa sobre sua capacidade de usar um computador, [...] não se refere a subcompetências de componentes simples, como a formatação de disquetes ou inserir fórmulas em uma planilha. Em vez disso, incorpora juízos sobre a sua própria capacidade de aplicar essas habilidades em tarefas mais amplas como elaboração de relatórios escritos ou análise de dados financeiros. (Compeau \& Higgins, 1995, p.2).

Para Claggett e Goodhue (2011), a definição de Compeau e Higgins (1995) manteve-se fiel à conceituação de autoeficácia de Bandura, uma vez que para eles o construto foi definido com as mesmas expressões que Bandura utilizou em sua definição de autoeficácia de 1986, referindo-se aos julgamentos das pessoas sobre suas capacidades para organizar e executar cursos de ação necessários para atingir tipos designados de performances.

Outra definição de AEC apresentada com frequência nos artigos é a de Gist (1987), que conceitua autoeficácia como a crença de um indivíduo na própria capacidade de realizar uma tarefa. Conforme a crítica de Claggett e Goodhue (2011), essa definição apresenta problemas em seu significado quando faz referência ao construto autoeficácia. Segundo Claggett e Goodhue (2011), apesar de Gist citar Bandura em seus artigos, há uma diferença entre a definição de Bandura (1986), que enfatiza as capacidades geradoras de autoeficácia, e a definição de Gist (1987), que parece enfatizar a autoavaliação de habilidades mais básicas ou pontuais.

A definição de Murphy, Coover e Owen (1989) também é citada em diversos estudos e, assim como Gist (1987), faz referência à autopercepção sobre as habilidades específicas que o indivíduo possui ao utilizar o computador e seus recursos. Murphy et al. (1989), após análise do uso do conceito, definem AEC como a percepção do indivíduo sobre suas próprias capacidades em manusear o computador, no que se refere a conhecimentos de informática e habilidades específicas.

Torkzadech, Chang e Demirhan (2006) afirmam que a AEC desempenha um papel significativo na decisão de um indivíduo de utilizar (ou não) o computador e seus recursos, e no quanto tais usuários estão abertos a adquirir novas habilidades relacionadas ao uso dessa ferramenta e seus softwares. Marakas et al. (1998) corroboram o pensamento de Torkzadeh et al. (2006) e afirmam que aqueles que se percebem com alta autoeficácia no uso de computadores tendem a ser mais eficientes na aquisição de novas competências associadas à utilização dessa ferramenta.

Para Eastin e LaRose (2000), a relação entre autoeficácia e utilização bem sucedida do computador pessoal pode ser considerada óbvia. Para eles, o computador pessoal apresenta-se por meio de uma tecnologia complexa e um tanto incômoda, exigindo habilidades específicas e treinamento para ser operada com êxito. Nesse contexto, a autoeficácia se torna essencial para muitos novatos superarem o medo em suas primeiras experiências com computadores.

Aprofundando a análise sobre esse tema, vários autores diferenciam autoeficácia geral e específica no uso de computadores. A autoeficácia geral no uso dos computadores refere-se ao julgamento de um indivíduo sobre suas habilidades em tarefas genéricas em um computador, sem associá-las ao desempenho no uso de software, aplicativo ou ambientes virtuais específicos.

Hasan (2006) relaciona autoeficácia à percepção do indivíduo sobre a execução de tarefas, programas ou softwares específicos e bem característicos como, por exemplo, um programa estatístico ou de edição de fotos. Estudos como de Hasan (2003), Agarwal, Sambamurthy e Stair (2000) encontraram uma relação positiva entre autoeficácia geral e específica no uso dos computadores.

Em pesquisas realizadas na área de TD\&E, vários autores concordam que o estudo da AEC é uma característica individual relevante a ser considerada nas investigações sobre processos e resultados de situações de treinamento e ensino em que o computador é ferramenta essencial na aprendizagem 
(Chou \& Wang, 2000). Compeau e Higgins (1995) indicaram que a percepção de uma pessoa sobre o grau de AEC afeta significativamente suas expectativas sobre o seu desempenho.

Os estudos supracitados e os analisados mais adiante demonstram a importância de mais revisões da produção de conhecimentos sobre o tema, visando ao aprimoramento das medidas e das definições do construto de AEC em contextos educacionais e corporativos de aprendizagem mediada por computador ou por outras tecnologias.

De fato, a aprendizagem por meio de recursos eletrônicos, como a internet ou os ambientes virtuais de aprendizagem, é uma tendência educacional de fácil confirmação, especialmente quando se observa a adoção em massa de processos educacionais a distância no contexto atual de TD\&E. Portanto, avaliar o perfil do participante de cursos ou treinamentos a distância é imprescindível para o sucesso das ações relacionadas à área de TD\&E, que adota cada vez mais essa forma de ensino-aprendizagem em suas estratégias.

Considerando todos os pontos apresentados, propõe-se como problema de pesquisa uma breve revisão sobre estudos internacionais que abordaram o tema da autoeficácia no uso de computadores em situações de aprendizagem, a fim de oferecer à comunidade científica uma análise comparativa de estudos recentes que associaram esse construto e o desempenho de aprendizes durante e após a realização de cursos ou na aprendizagem de novos conhecimentos ou competências. A seguir será apresentado o método adotado nesta revisão de literatura sobre a autoeficácia no uso de computadores.

\section{MÉTODO}

Esta revisão de literatura foi realizada por meio da identificação, seleção e análise de estudos que investigaram a autoeficácia no uso de computadores por meio da aplicação de escalas. Com os resultados obtidos, objetivou-se analisar as definições desse construto e descrever brevemente as escalas psicométricas adotadas, os principais resultados dessas pesquisas e as lacunas a serem supridas por outros estudos.

Ao iniciar a pesquisa, foram definidas as palavras-chave computer self-efficacy (CSE), training e learning (autoeficácia no uso do computador, treinamento e aprendizagem, respectivamente) como filtros para a seleção dos artigos, os quais serviram de base para esta revisão. Inicialmente, foram considerados todos aqueles que apresentaram a expressão computer self-efficacy combinada com as palavras-chave training ou learning no título, no resumo ou nas palavras-chave. Foram encontrados aproximadamente 80 artigos, tanto empíricos quanto teóricos, que abordavam o tema da AEC em situações de ensino ou de treinamento. Após essa primeira busca, outro filtro foi aplicado, selecionando-se apenas as publicações que apresentavam relatos de pesquisas empíricas e que haviam adotado medidas e escalas de avaliação da AEC em amostras de aprendizes. Artigos de caráter teórico, capítulos de livros e textos que não utilizavam ou não descreviam adequadamente a medida psicométrica utilizada ou citada foram descartados da amostra. Restaram 30 artigos publicados em revistas científicas com corpo editorial e revisão por pares.

Praticamente toda a pesquisa foi realizada de forma eletrônica, por meio do Portal Capes Periódicos e bibliotecas virtuais: PsycINFO, Web of Science, BVS Psicologia ULAPSI Brasil e Scielo. Buscas adicionais foram feitas em periódicos científicos como: Computers in Human Behavior, Annual Review of Psychology e Journal of Applied Psychology, visando à obtenção de uma amostra representativa da produção de conhecimentos na área.

As buscas compreenderam artigos e textos científicos publicados no período de 1998 a 2011. Marakas et. al (1998) apresentaram uma extensa revisão de literatura internacional nessa área, abrangendo artigos publicados nos anos de 1985 a 1996, que avaliaram a produção de conhecimentos em diversos aspectos, como método, características da amostra, variáveis independentes (VIs) e variáveis dependentes (VDs), natureza da tarefa que exigia do participante o uso do computador, instrumento de medida utilizado e achados. Neste estudo, os 30 artigos foram analisados de acordo com categorias de conteúdo similares às adotadas por Marakas et. al (1998). Os trabalhos encontrados, bem como seus autores, as variáveis investigadas, as técnicas e medidas adotadas e os resultados obtidos são apresentados na Tabela 1 . Além desses 30 trabalhos, também foram considerados quatro artigos que estudaram a autoeficácia geral em contextos de treinamento (Colquitt, Le Pine, \& Noe 2000; Frayne \& Geringer, 2000; Lorenz, Gregory, \& Davis, 2000; Meneses \& Abbad, 2003). 
TABELA 1. Sumário cronológico sobre o tema autoeficácia no uso de computadores (AEC)

\begin{tabular}{|c|c|c|c|c|c|c|}
\hline Ano & Autor(es) & $\begin{array}{l}\text { Ocupação e país } \\
\text { da amostra }\end{array}$ & $\begin{array}{l}\text { Conceito de } \\
\text { AEC utilizada }\end{array}$ & Escala de AEC adotada & Método & Principais resultados \\
\hline $1998(1)$ & Brosnan & $\begin{array}{l}\text { Estudantes } \\
\text { universitários da } \\
\text { Inglaterra }\end{array}$ & Gist et al., (1989) & $\begin{array}{l}\text { Gist et al.(1989) } \\
\text { Escala de AEC específica - alfa não informado. }\end{array}$ & $\begin{array}{l}\text { - Survey } \\
\text { - Análise de regressão }\end{array}$ & $\begin{array}{l}\text { - Quanto maior o nível de AEC específica percebida, maior } \\
\text { o número de tentativas em resolver a tarefa designada no } \\
\text { computador. }\end{array}$ \\
\hline $1998(2)$ & Karsten e Roth & $\begin{array}{l}\text { Estudantes de } \\
\text { administração dos } \\
\text { Estados Unidos }\end{array}$ & $\begin{array}{l}\text { Compeau e } \\
\text { Higgins (1995) }\end{array}$ & $\begin{array}{l}\text { Murphy et al. (1989) } \\
\text { Escala de AEC específica - alfa não informado. }\end{array}$ & $\begin{array}{l}\text { - Survey } \\
\text { - Pré-testes e pós-testes } \\
\text { - Correlações } \\
\text { - Regressão tipo } \\
\text { stepwise }\end{array}$ & $\begin{array}{l}\text { - Experiência prévia com computador mostrou-se positivamente } \\
\text { correlacionada com as percepções iniciais de AEC. } \\
\text { Estudantes mais próximos de se formarem apresentaram nível } \\
\text { mais elevado de AEC. }\end{array}$ \\
\hline 1999 (3) & $\begin{array}{l}\text { Torkzadeh, } \\
\text { Pflughoeft e Hall }\end{array}$ & $\begin{array}{l}\text { Estudantes de } \\
\text { administração dos } \\
\text { Estados Unidos }\end{array}$ & Gist et al. (1989) & $\begin{array}{l}\text { Murphy et al. (1989), adaptado por Torkzadeh e Koufteros } \\
(1994) \\
\text { Escala de AEC específica } \\
4 \text { fatores ( } 28 \text { itens): } \\
\text { 1. Habilidades iniciais }(\alpha=0,93) \\
\text { 2. Habilidades avançadas }(\alpha=0,88) \\
\text { 3. Habilidades de manusear arquivos e programas }(\alpha=0,90) \\
\text { 4. Habilidades de manusear Mainframe }(\alpha=0,95) \\
\text { Alfa total da escala }(\alpha=0,95)\end{array}$ & $\begin{array}{l}\text { - Análise fatorial } \\
\text { (rotação varimax) } \\
\text { - Survey } \\
\text { - Pré-testes e pós-testes }\end{array}$ & $\begin{array}{l}\text { - A frequência em um treinamento introdutório sobre } \\
\text { computadores mostrou-se positivamente correlacionado ao grau } \\
\text { de AEC. } \\
\text { - Essa correlação apresentou-se mais forte em usuários que } \\
\text { também apresentaram uma atitude positiva frente ao uso de } \\
\text { computadores. }\end{array}$ \\
\hline $2000(4)$ & $\begin{array}{l}\text { Agarwal, } \\
\text { Sambamurthy } \\
\text { e Stair }\end{array}$ & $\begin{array}{l}\text { Universitários } \\
\text { norte-americanos } \\
\text { participantes de um } \\
\text { curso introdutório } \\
\text { sobre computação }\end{array}$ & $\begin{array}{l}\text { Compeau e } \\
\text { Higgins (1995) }\end{array}$ & $\begin{array}{l}\text { Compeau, } \\
\text { Higgins (1995), } \\
\text { Escala de AEC } \\
\text { geral, } 10 \text { itens, } \alpha=0,92 \\
\text { Escala de autoeficácia específica para os programas Windows } \\
(7 \text { itens, } \alpha=0,80 \text { ) e Lótus } 1-2-3 \text { ( } 9 \text { itens, } \alpha=0,89)\end{array}$ & $\begin{array}{l}\text { - Pré-testes e pós-testes } \\
\text { foram aplicados em três } \\
\text { momentos diferentes } \\
\text { durante o curso } \\
\text { - Equação estrutural }\end{array}$ & $\begin{array}{l}\text { - A variável inovação pessoal com uso de computadores } \\
\text { apresentou-se antecedente ao nível de AEC pré-treinamento. } \\
\text { - AEC geral pré-treinamento apresentou-se como variável } \\
\text { antecedente ao nível AEC específico pós-treinamento. }\end{array}$ \\
\hline $2000(5)$ & Chou e Wang & $\begin{array}{l}\text { Estudantes do último } \\
\text { ano do ensino médio } \\
\text { de uma escola de } \\
\text { Taiwan }\end{array}$ & $\begin{array}{l}\text { Compeau e } \\
\text { Higgins (1995) }\end{array}$ & $\begin{array}{l}\text { Murphy et al. (1989) } \\
\text { Escala de AEC específica, traduzida e validada para o chinês } \\
N^{\circ} \text { de fatores não informados. } \\
\alpha=0,97\end{array}$ & $\begin{array}{l}\text { - Pré-testes e pós- } \\
\text { testes } \\
\text { - Testes t } \\
\text { - Análise da variância } \\
\text { - Correlação }\end{array}$ & $\begin{array}{l}\text { - Um aumento do nível de AEC apresentou-se positivamente } \\
\text { correlacionado em alunas que participaram do método } \\
\text { instrucional de treinamento. } \\
\text { - Um aumento do nível de AEC apresentou-se positivamente } \\
\text { correlacionado em alunos que participaram do método } \\
\text { comportamental desse mesmo treinamento. }\end{array}$ \\
\hline $2000(6)$ & $\begin{array}{l}\text { Durndell, Haag } \\
\text { e Laithwaite }\end{array}$ & $\begin{array}{l}\text { Universitários que } \\
\text { estavam completando } \\
\text { o } 1^{\circ} \text { ano de faculdade } \\
\text { na Escócia e na } \\
\text { Romênia }\end{array}$ & $\begin{array}{l}\text { O artigo não fez } \\
\text { nenhum referência } \\
\text { específica quanto } \\
\text { à definição de } \\
\text { AEC adotada. }\end{array}$ & $\begin{array}{l}\text { Versão de Torkzadeh, Koufteros (1994) da escala de Murphy et } \\
\text { al. (1989) } \\
3 \text { fatores: } \\
\text { F1. Habilidades iniciais } \\
\text { F2. Habilidades avançadas } \\
\text { F3. Habilidades em arquivos e softwares } \\
\text { Na amostra romena, o alfa se apresentou igual a 0,94, na } \\
\text { amostra escocesa } \alpha=0,95 \text {. }\end{array}$ & $\begin{array}{l}\text { - Survey } \\
\text { - ANOVA } \\
\text { - Correlação }\end{array}$ & $\begin{array}{l}\text { - Os homens mostraram-se mais confiantes que as mulheres } \\
\text { nos fatores da escala de AEC que avaliaram conhecimentos. } \\
\text { - Os três fatores da escala de AEC mostraram-se positivamente } \\
\text { correlacionados entre si. }\end{array}$ \\
\hline $2000(7)$ & Eastin e LaRose & $\begin{array}{l}\text { Estudantes } \\
\text { universitários } \\
\text { residentes nos } \\
\text { Estados Unidos }\end{array}$ & $\begin{array}{l}\text { Compeau e } \\
\text { Higgins (1995) }\end{array}$ & $\begin{array}{l}\text { Autoeficácia no uso da internet, } \\
\text { Eastin e LaRose (2000) } \\
\text { Unifatorial - } 8 \text { itens, } \\
\alpha=0,93\end{array}$ & $\begin{array}{l}\text { - Análise fatorial } \\
\text { - Correlações }\end{array}$ & $\begin{array}{l}\text { - As variáveis "experiência anterior com a internet", "expectativas } \\
\text { positivas sobre o uso da internet" e "frequência de uso da } \\
\text { internet" mostraram-se positivamente correlacionadas com nível } \\
\text { de autoeficácia do estudante. } \\
\text { - Estresse e autodepreciação apresentaram-se negativamente } \\
\text { correlacionados com o nível de autoeficácia. }\end{array}$ \\
\hline
\end{tabular}




\begin{tabular}{|c|c|c|c|c|}
\hline Ano & Autor(es) & $\begin{array}{l}\text { Ocupação e país } \\
\text { da amostra }\end{array}$ & $\begin{array}{l}\text { Conceito de } \\
\text { AEC utilizada }\end{array}$ & Escala de AEC adotada \\
\hline $2000(8)$ & $\begin{array}{l}\text { Kagima e } \\
\text { Hausafus }\end{array}$ & $\begin{array}{l}\text { Professores } \\
\text { universitários da } \\
\text { lowa University - } \\
\text { Estados Unidos }\end{array}$ & $\begin{array}{l}\text { Compeau e } \\
\text { Higgins (1995) }\end{array}$ & $\begin{array}{l}\text { Murphy et al. (1989) adaptado, incluindo itens específicos sobre } \\
\text { o programa ICN } \text { - lowa C. Network. } \\
\text { Escala de AEC específica } \\
4 \text { fatores ( } 28 \text { itens): } \\
\text { 1. Communicação eletrônica } \\
\alpha=0,83 \\
\text { 2. Autoeficácia no uso de computadores } \\
\alpha=93 \\
\text { 3. Autoeficácia no uso do e-mail } \\
\alpha=0,77 \\
\text { 4. Autoeficácia em usar a web } \\
\alpha=0,90 \\
\text { Alfa total da escala }(\alpha=0,94)\end{array}$ \\
\hline $2000(9)$ & $\begin{array}{l}\text { Salanova, Grau, } \\
\text { Cifre e Llorens }\end{array}$ & $\begin{array}{l}\text { Trabalhadores } \\
\text { espanhóis } \\
\text { que utilizam } \\
\text { computadores no } \\
\text { trabalho }\end{array}$ & $\begin{array}{l}\text { Murphy, Coover e } \\
\text { Owen (1989) }\end{array}$ & $\begin{array}{l}\text { Beas, Agut, Salanova e Grau, (1999) } \\
\text { Alfa total da escala }(\alpha=0,79) \\
\text { Escala de AEC geral } \\
\text { Número de itens e fatores não informados }\end{array}$ \\
\hline $\begin{array}{l}2001 \\
(10)\end{array}$ & Khorrami-Arani & $\begin{array}{l}\text { Estudantes do ensino } \\
\text { médio - Austrália }\end{array}$ & $\begin{array}{l}\text { Compeau e } \\
\text { Higgins (1995) }\end{array}$ & $\begin{array}{l}\text { Murphy et al. (1989) com adaptações. } \\
\text { Escala de AEC específica. } \\
3 \text { fatores }(30 \text { itens) } \\
\text { F1. Habilidades iniciais } \\
\text { F2. Habilidades avançadas } \\
\text { F3. Habilidades em arquivos e softwares } \\
\text { Alfa total da escala } \alpha=0,95\end{array}$ \\
\hline $\begin{array}{l}2002 \\
(11)\end{array}$ & Durndell e Haag & $\begin{array}{l}\text { Universitários de } \\
\text { uma faculdade na } \\
\text { Romênia }\end{array}$ & $\begin{array}{l}\text { Compeau e } \\
\text { Higgins (1995) }\end{array}$ & $\begin{array}{l}\text { Murphy et al. (1989), adaptado por Torkzadeh e Koufteros } \\
(1994) \\
\text { Escala de AEC específica, } 4 \text { fatores ( } 28 \text { itens), validado para a } \\
\text { língua local. } \\
(\alpha=0,95)\end{array}$ \\
\hline $\begin{array}{l}2002 \\
(12)\end{array}$ & Potosky & $\begin{array}{l}\text { Programadores } \\
\text { recém-contratados } \\
\text { e que participaram } \\
\text { de um treinamento - } \\
\text { Estados Unidos }\end{array}$ & Gist et al. (1989) & $\begin{array}{l}\text { A escala de Gist et al. (1989) adaptada. } \\
\text { Unifatorial } \alpha=0,94 \\
\text { Escala de autoeficácia específica sobre SQL (um programa } \\
\text { específico de computador) }\end{array}$ \\
\hline $\begin{array}{l}2003 \\
(13)\end{array}$ & Hasan & $\begin{array}{l}\text { Universitários de uma } \\
\text { Universidade pública } \\
\text { dos Estados Unidos } \\
\text { inscritos em uma } \\
\text { disciplina de Sistema } \\
\text { de informações }\end{array}$ & $\begin{array}{l}\text { Compeau e } \\
\text { Higgins (1995) }\end{array}$ & $\begin{array}{l}\text { Compeau, Higgins (1995) } \\
\text { Escala de AEC geral, } 10 \text { itens, } \alpha=0,92\end{array}$ \\
\hline
\end{tabular}

Método

- Análises descritivas - Testes t
- ANOVA

Regressão múltipla hierárquica

Validação das escalas Análise da correlação entre os fatores das scalas apresentadas

Testes $\mathrm{t}$

Correlação

Regressão

- Análise das correlações Regressões tipo hierárquica

Análise de regressão

\section{Principais resultados}

Professores do sexo masculino apresentaram maior AEC. Professores que dão aulas em cursos relacionados às ciências do consumidor ou da família e com mais de dez anos de faculdade apresentaram menor grau de AEC que professores
com menos de dez anos de docência e que lecionavam em cursos da área da educação e agricultura.

- A frequência do uso de computadores e a participação em treinamentos apresentaram-se positivamente correlacionadas com a AEC.

- Elevados níveis de AEC e de formação em informática foram associados com uma diminuição da exaustão do profissional que lida diretamente com computadores.

- AEC mostrou-se correlacionado com a presença das três variáveis (ansiedade, confiança e agradabilidade) e em maio grau com a confiança do aluno no uso de computadores.

- Estudantes do sexo masculino apresentaram maior grau de AEC, menor grau de ansiedade e atitudes mais positivas em relação ao uso de computador ou internet do que estudantes do sexo feminino.

Conhecimentos anteriores sobre o uso do computador apresentaram-se positivamente correlacionados às crenças de autoeficácia pós-treinamentos.

AEC geral mostrou-se positivamente correlacionada à autoeficácia no uso de software SQL pós-treinamento.

- Experiência com programação de computadores e aplicativo gráficos apresentaram-se como variável antecedente à AEC. 


\begin{tabular}{|c|c|c|c|c|c|c|}
\hline Ano & Autor(es) & $\begin{array}{l}\text { Ocupação e país } \\
\text { da amostra }\end{array}$ & $\begin{array}{l}\text { Conceito de } \\
\text { AEC utilizada }\end{array}$ & Escala de AEC adotada & Método & Principais resultados \\
\hline $\begin{array}{l}2003 \\
(14)\end{array}$ & $\begin{array}{l}\text { Torkzadeh, } \\
\text { Koufteros e } \\
\text { Pflughoeft }\end{array}$ & $\begin{array}{l}\text { Universitários } \\
\text { do curso de } \\
\text { administração } \\
\text { de duas grandes } \\
\text { universidades dos } \\
\text { Estados Unidos }\end{array}$ & $\begin{array}{l}\text { Compeau e } \\
\text { Higgins (1995) }\end{array}$ & $\begin{array}{l}\text { Torkzadeh \& } \\
\text { Koufteros, (1994) Adaptada de Murphy (1989) - Escala de AEC } \\
\text { específica: } \\
\text { F1. Habilidades iniciais } \\
(\alpha=0,91) \\
\text { F2. Habilidades com arquivos e softwares } \\
(\alpha=0,91) \\
\text { F3. Habilidades avançadas } \\
(\alpha=0,91) \\
\text { F4. Habilidades em mainfraine }(\alpha=0,89)\end{array}$ & $\begin{array}{l}\text { - Pré-testes e pós-testes } \\
\text { - Análise fatorial } \\
\text { confirmatória } \\
\text { (LISREL) } \\
\text { - Chi-quadrado } \\
\text { - Diferenças das médias }\end{array}$ & $\begin{array}{l}\text { - Este estudo corroborou os resultados da análise confirmatória } \\
\text { do instrumento AEC originalmente desenvolvido por Murphy et } \\
\text { al. (1989) e previamente validado por Torkzadeh e Koufteros } \\
\text { (1994). }\end{array}$ \\
\hline $\begin{array}{l}2004 \\
(15)\end{array}$ & $\begin{array}{l}\text { Barbeite e } \\
\text { Weiss, }\end{array}$ & $\begin{array}{l}\text { Membros da } \\
\text { população que } \\
\text { participaram de um } \\
\text { painel de pesquisa } \\
\text { residentes nos } \\
\text { Estados Unidos }\end{array}$ & $\begin{array}{l}\text { Compeau e } \\
\text { Higgins (1995) }\end{array}$ & $\begin{array}{l}\text { Murphy et al. (1989) adaptada } \\
\text { Escala de AEC específica } \\
2 \text { Fatores: } \\
\text { F1. Habilidades iniciais }(\alpha=0,83) \\
\text { F2. Habilidades com arquivos e softwares }(\alpha=0,85)\end{array}$ & $\begin{array}{l}\text { - Análises fatoriais das } \\
\text { escalas utilizadas } \\
\text { - Regressão múltipla }\end{array}$ & $\begin{array}{l}\text { - AEC mostrou-se positivamente correlacionada à quantidade de } \\
\text { anos de uso pessoal de computadores. } \\
\text { - AEC apresentou-se como variável antecedente à percepção de } \\
\text { conforto no uso de computadores. }\end{array}$ \\
\hline $\begin{array}{l}2005 \\
(16)\end{array}$ & $\begin{array}{l}\text { Noiwan, Piyawat } \\
\text { e Norcio }\end{array}$ & $\begin{array}{l}\text { Universiários de } \\
\text { uma faculdade da } \\
\text { Tailandia }\end{array}$ & $\begin{array}{l}\text { Compeau e } \\
\text { Higgins (1995) }\end{array}$ & Kinzie, et al. (1994), 46 itens & $\begin{array}{l}\text { Kinzie, Delcourt, e } \\
\text { Powers (1994) - Escala } \\
\text { de EAC específica }\end{array}$ & $\begin{array}{l}\text { - Os usuários novatos têm níveis mais baixos AEC do que } \\
\text { usuários mais experiêntes. } \\
\text { - Universiários que apresentaram uma percepção maior de AEC } \\
\text { atitudes positivas relacionadas ao uso do computador (modelo } \\
\text { TAM). }\end{array}$ \\
\hline $\begin{array}{l}2006 \\
(17)\end{array}$ & Brinkerhoff & $\begin{array}{l}\text { Professores de } \\
\text { escolas públicas do } \\
\text { Novo México (EUA) } \\
\text { e participantes de um } \\
\text { projeto para incentivo } \\
\text { no uso de NTICs na } \\
\text { educação }\end{array}$ & $\begin{array}{l}\text { O artigo não fez } \\
\text { nenhum referência } \\
\text { específica quanto } \\
\text { à definição de } \\
\text { AEC adotada }\end{array}$ & $\begin{array}{l}\text { Cassidy, Eachus (2002) Versão adaptada } \\
\text { Escala de AEC geral, } 20 \text { itens, } \alpha=0,94\end{array}$ & $\begin{array}{l}\text { - Pré-testes e pós-testes } \\
\text { foram aplicados } \\
\text { - ANOVA }\end{array}$ & $\begin{array}{l}\text { - Participação efetiva no curso sobre NTICs apresentou- } \\
\text { se positivamente correlacionada ao nível de AEC e de } \\
\text { autoavaliação de competências tecnológicas. }\end{array}$ \\
\hline $\begin{array}{l}2006 \\
(18)\end{array}$ & Hasan & $\begin{array}{l}\text { Estudantes } \\
\text { universitários dos } \\
\text { Estados Unidos }\end{array}$ & $\begin{array}{l}\text { Compeau e } \\
\text { Higgins (1995) e } \\
\text { Gist et al. (1989) }\end{array}$ & $\begin{array}{l}\text { Compeau e Higgins (1995). } \\
\text { Escala de AEC geral, } 10 \text { itens, } \alpha=0,94 \\
\text { Marakas, Yi e Johnson (1998) } \\
\text { Escala de AEC específica, } 9 \text { itens, } \alpha=0,85\end{array}$ & $\begin{array}{l}\text { - Pré-testes e pós-testes } \\
\text { - Correlação } \\
\text { - Regressão hierárquica }\end{array}$ & $\begin{array}{l}\text { - AEC geral apresentou-se positivamente correlacionada ao } \\
\text { nível de AEC específica e ao grau de percepção da facilidade no } \\
\text { uso de computadores, influenciando-a positivamente. } \\
\text { - AEC específica confirmou-se como variável antecedente à } \\
\text { percepção de facilidade no uso de computadores e à intenção } \\
\text { de seu uso, influenciando-a positivamente. }\end{array}$ \\
\hline $\begin{array}{l}2006 \\
(19)\end{array}$ & $\mathrm{Ng}$ & $\begin{array}{l}\text { Trabalhadores } \\
\text { de indústrias de } \\
\text { Shangai, China }\end{array}$ & $\begin{array}{l}\text { Compeau e } \\
\text { Higgins (1995) }\end{array}$ & $\begin{array}{l}\text { Compeau e Higgins (1995) } \\
\text { Escala de AEC geral, } 9 \text { itens, } \alpha=0,94\end{array}$ & - Equação estrutural & $\begin{array}{l}\text { - AEC geral confirmou-se como variável antecedente ao uso do } \\
\text { computador no trabalho, influenciando de forma positiva. }\end{array}$ \\
\hline $\begin{array}{l}2006 \\
(20)\end{array}$ & $\begin{array}{l}\text { Papasratorn, } \\
\text { Wangpipatwong }\end{array}$ & $\begin{array}{l}\text { Universitários de um } \\
\text { curso introdutório ao } \\
\text { uso de computadores } \\
\text { de Bangkok- } \\
\text { Tailândia }\end{array}$ & $\begin{array}{l}\text { O artigo não fez } \\
\text { nenhum referência } \\
\text { específica quanto } \\
\text { à definição de } \\
\text { AEC adotada }\end{array}$ & $\begin{array}{l}\text { Murphy et al. (1989) adaptada } \\
\text { Escala específica de AEC }\end{array}$ & - Análise de regressão & $\begin{array}{l}\text { - AEC e atitude favorável sobre o uso do computador } \\
\text { confirmaram-se como variáveis antecedentes ao desempenho } \\
\text { dos alunos no curso e-learning, influenciando de forma positiva. }\end{array}$ \\
\hline
\end{tabular}




\begin{tabular}{|c|c|c|c|c|c|c|}
\hline Ano & Autor(es) & $\begin{array}{l}\text { Ocupação e país } \\
\text { da amostra }\end{array}$ & $\begin{array}{l}\text { Conceito de } \\
\text { AEC utilizada }\end{array}$ & Escala de AEC adotada & Método & Principais resultados \\
\hline $\begin{array}{l}2006 \\
(21)\end{array}$ & $\begin{array}{l}\text { Torkzadech, } \\
\text { Chang, e } \\
\text { Demirhan }\end{array}$ & $\begin{array}{l}\text { Universitários } \\
\text { de um curso de } \\
\text { administração dos } \\
\text { Estados Unidos }\end{array}$ & $\begin{array}{l}\text { Compeau e } \\
\text { Higgins (1995) }\end{array}$ & $\begin{array}{l}\text { Murphy et al. (1989) adaptada. } \\
\text { Escala específica de AEC, } 25 \text { itens, } \alpha \text { total= } 0,95\end{array}$ & $\begin{array}{l}\text { - Pré-testes, Pós-testes } \\
\text { - ANOVA }\end{array}$ & $\begin{array}{l}\text { - Atitudes positivas do usuário frente ao uso do computador } \\
\text { e baixa ansiedade confirmaram-se correlacionados ao } \\
\text { fortalecimento da AEC. }\end{array}$ \\
\hline $\begin{array}{l}2007 \\
(22)\end{array}$ & $\begin{array}{l}\text { Mcilroy, Sadler e } \\
\text { Boojawon }\end{array}$ & $\begin{array}{l}\text { Estudantes de } \\
\text { graduação da } \\
\text { Universidade de } \\
\text { Liverpool JohnMoores } \\
\text { - Inglaterra }\end{array}$ & $\begin{array}{l}\text { O artigo não } \\
\text { fez nenhuma } \\
\text { referência } \\
\text { especíica quanto } \\
\text { à definição de } \\
\text { AEC adotada }\end{array}$ & $\begin{array}{l}\text { Versão de Torkzadeh, Koufteros (1994) da escala de Murphy } \\
\text { et al. } \\
\text { Escala de AEC específica, } 29 \text { itens, } \alpha=0,97\end{array}$ & $\begin{array}{l}\text { - Correlações } \\
\text { - MANOVA } \\
\text { - Regressão múltipla }\end{array}$ & $\begin{array}{l}\text { - Os estudantes que relataram qualquer fobia frente ao } \\
\text { computador ou baixa AEC apresentaram-se menos propensos a } \\
\text { utilizar os laboratórios de computadores da universidade. } \\
\text { - Experiência prévia e uso doméstico com computador e de } \\
\text { frequência em um curso de informática confirmaram-se como } \\
\text { variáveis antecedentes à presença de alto grau de AEC. }\end{array}$ \\
\hline $\begin{array}{l}2008 \\
(23)\end{array}$ & Saleh & $\begin{array}{l}\text { Professores de uma } \\
\text { universidade pública } \\
\text { do Líbano }\end{array}$ & $\begin{array}{l}\text { Compeau e } \\
\text { Higgins (1995) } \\
\text { Murphy, Coover e } \\
\text { Owen (1989) }\end{array}$ & $\begin{array}{l}\text { Cassidy e Eachus (2002) a escala foi adaptada e validada para } \\
\text { o uso nesta pesquisa, realizada no Líbano. } \\
\text { Escala de AEC geral, } 20 \text { itens. }\end{array}$ & $\begin{array}{l}\text { Análises descritivas e } \\
\text { correlacionais }\end{array}$ & $\begin{array}{l}\text { - Professores com mais acesso à tecnologia, ou que lecionam } \\
\text { nesta área, apresentaram maiores índices de AEC, se } \\
\text { comparado com o índice dos outros professores. }\end{array}$ \\
\hline $\begin{array}{l}2008 \\
(24)\end{array}$ & $\begin{array}{l}\text { Santhanam, } \\
\text { Sasidharan e } \\
\text { Webster }\end{array}$ & $\begin{array}{l}\text { Estudantes } \\
\text { universitários de uma } \\
\text { faculdade pública } \\
\text { dos Estados Unidos } \\
\text { frequentaram um } \\
\text { curso realizado por } \\
\text { meio do computador }\end{array}$ & $\begin{array}{l}\text { Compeau e } \\
\text { Higgins (1995) }\end{array}$ & $\begin{array}{l}\text { Computer Learning Self-Efficacy, de Santhanam, Sasidharan, } \\
\text { Webster (2008) } \\
\text { Escala de autoeficácia específica }-7 \text { itens }\end{array}$ & $\begin{array}{l}\text { - Pré-testes, Pós-testes } \\
\text { - Testes t (diferenças } \\
\text { das médias) } \\
\text { - Regressão tipo } \\
\text { hierárquica }\end{array}$ & $\begin{array}{l}\text { - Os participantes que foram induzidos a seguir estratégias de } \\
\text { aprendizagem (que incluía o gerenciamento da AEC) tiveram } \\
\text { melhores resultados da aprendizagem do que aqueles que não } \\
\text { foram convencidos a fazê-lo. }\end{array}$ \\
\hline $\begin{array}{l}2009 \\
(25)\end{array}$ & $\begin{array}{l}\text { Burkhard e } \\
\text { Roldan }\end{array}$ & $\begin{array}{l}\text { Universitários } \\
\text { do curso de } \\
\text { administração nos } \\
\text { Estados Unidos }\end{array}$ & $\begin{array}{l}\text { Compeau e } \\
\text { Higgins (1995) }\end{array}$ & $\begin{array}{l}\text { Compeu e Higgins (1995) - Adaptada } \\
\text { AEC Específica } \\
2 \text { fatores: } \\
\text { (1) tarefas simples; } \\
\text { (2) complexas. } \\
\text { Alfas não informados. }\end{array}$ & $\begin{array}{l}\text { - Survey } \\
\text { - pré-testes e pós-testes }\end{array}$ & $\begin{array}{l}\text { - Os resultados sugeriram que o fortalecimento da AEC é } \\
\text { altamente influenciado pela realização de tarefas complexas no } \\
\text { computador. }\end{array}$ \\
\hline $\begin{array}{l}2009 \\
(26)\end{array}$ & $\begin{array}{l}\text { Hsu, Wang e } \\
\text { Chiu }\end{array}$ & $\begin{array}{l}\text { Alunos de um MBA } \\
\text { (EaD) nos Estados } \\
\text { Unidos }\end{array}$ & $\begin{array}{l}\text { Compeau e } \\
\text { Higgins (1995) }\end{array}$ & $\begin{array}{l}\text { Escala específica sobre o uso de programas estatísticos. } \\
\text { Medida construída por meio de uma adaptadação da escala de } \\
\text { Compeau e Higgins (1995) } \\
\alpha=0,86\end{array}$ & $\begin{array}{l}\text { - Análise fatorial } \\
\text { confirmatória (path } \\
\text { analytic) } \\
\text { - Teste do qui- } \\
\text { quadrado. }\end{array}$ & $\begin{array}{l}\text { - Atitudes no uso de computadores e autoeficácia no uso } \\
\text { de programas estatísticos mostraram-se como fatores } \\
\text { antecedentes ao uso de programas estatísticos. }\end{array}$ \\
\hline $\begin{array}{l}2009 \\
(27)\end{array}$ & Tzeng & $\begin{array}{l}\text { Estudantes que } \\
\text { participavam de um } \\
\text { curso sobre Mapas } \\
\text { conceituais, em } \\
\text { Taiwan }\end{array}$ & $\begin{array}{l}\text { Compeau e } \\
\text { Higgins (1995) }\end{array}$ & $\begin{array}{l}\text { General self-efficacy (GSE) Autoeficácia geral a= } 0,85 \text { (Duncan } \\
\& \text { McKeachie, 2005) } \\
\text { Specific self-efficacy (SSE) Escala de autoeficácia específica }-7 \\
\text { itens, relacionado ao Cmap Tools, } \alpha=0,76\end{array}$ & $\begin{array}{l}\text { - Análise fatorial } \\
\text { confirmatória } \\
\text { - Pré-testes e pós-testes } \\
\text { - ANOVA - Análise das } \\
\text { diferenças das médias }\end{array}$ & $\begin{array}{l}\text { - AEC geral apresentou-se positivamente correlacionada com o } \\
\text { grau de autoeficácia específica, relacionada ao uso do programa } \\
\text { de computador Cmap Tools. }\end{array}$ \\
\hline $\begin{array}{l}2010 \\
(28)\end{array}$ & $\begin{array}{l}\text { Madhavan, } \\
\text { Rachel, e } \\
\text { Phillips }\end{array}$ & $\begin{array}{l}\text { Estudantes da } \\
\text { Universidade da } \\
\text { Virgínia, Estados } \\
\text { Unidos }\end{array}$ & $\begin{array}{l}\text { Murphy et al } \\
\text { (1989) }\end{array}$ & Computer Self-Efficacy Scale, de Murphy et al. (1989) & - Correlações & $\begin{array}{l}\text { - Profissionais com alto grau de AEC perceberam o sistema de } \\
\text { informática avaliado como mais confiável, além de acessaram o } \\
\text { sistema com mais frequência. }\end{array}$ \\
\hline
\end{tabular}




\begin{tabular}{|c|c|c|c|c|c|c|}
\hline Ano & Autor(es) & $\begin{array}{l}\text { Ocupação e país } \\
\text { da amostra }\end{array}$ & $\begin{array}{l}\text { Conceito de } \\
\text { AEC utilizada }\end{array}$ & Escala de AEC adotada & Método & Principais resultados \\
\hline $\begin{array}{l}2011 \\
(29)\end{array}$ & $\begin{array}{l}\text { Ismail, Mahmud, } \\
\text { Nor, Ahmad e } \\
\text { Rahman }\end{array}$ & $\begin{array}{l}\text { Professores da } \\
\text { Malásia que utilizam } \\
\text { uma livraria virtual } \\
\text { de conteúdos } \\
\text { relacionados à } \\
\text { docência chamado } \\
\text { "EDUWEBT" }\end{array}$ & $\begin{array}{l}\text { Compeau e } \\
\text { Higgins (1995) }\end{array}$ & $\begin{array}{l}\text { Escala de autoeficácia especifica sobre duas situações: } \\
1 \text { - Confiança em usar a EDUWEBT } \\
2 \text { - Confiança em divulgar a EDUWEBT } \\
\text { Alfas entre } 0,757 \text { e } 0,898 \text {. }\end{array}$ & $\begin{array}{l}\text { - Análises fatoriais das } \\
\text { escalas aplicadas } \\
\text { - Análises de } \\
\text { correlações de Pearson }\end{array}$ & $\begin{array}{l}\text { - AEC apresentou forte correlação positiva com a percepção de } \\
\text { facilidade e utilidade da EduwebTV. }\end{array}$ \\
\hline $\begin{array}{l}2011 \\
(30)\end{array}$ & $\begin{array}{l}\text { Tams, Murphy e } \\
\text { Craig }\end{array}$ & $\begin{array}{l}\text { Estudantes de uma } \\
\text { universidade dos } \\
\text { Estados Unidos }\end{array}$ & $\begin{array}{l}\text { Compeau e } \\
\text { Higgins (1995) }\end{array}$ & $\begin{array}{l}\text { Compeau, Higgins (1995). } \\
\text { Escala de AEC geral, } 10 \text { itens. } \\
\text { Alfa não informado. }\end{array}$ & $\begin{array}{l}\text { - Análises de pré e } \\
\text { pós-testes } \\
\text { - Análise de correlação } \\
\text { entre grupos }\end{array}$ & $\begin{array}{l}\text { - Níveis adequados de AEC geral funcionam como um } \\
\text { mecanismo de enfrentamento, o que leva os indivíduos a } \\
\text { ter menos estresse ao usar o computador conjuntamente a } \\
\text { provocadas interrupções mediadas pela tecnologia, como por } \\
\text { exemplo, mensagens instantâneas. }\end{array}$ \\
\hline
\end{tabular}




\section{RESULTADOS}

Esta seção apresenta os resultados da análise da literatura na seguinte sequência: (1) aspectos metodológicos dos estudos (amostras de participantes, país no qual a pesquisa foi realizada, instrumentos de medida) e (2) os principais resultados desses estudos.

\section{Aspectos metodológicos dos estudos}

Conforme a Tabela 1, referente aos 30 artigos revisados, foi possível agrupar várias informações sobre diversos aspectos metodológicos das pesquisas sobre autoeficácia no uso de computadores, entre as quais a descrição das amostras de participantes dos estudos. Confirmou-se que 23 pesquisas (76\%) adotaram amostras de estudantes, sendo que 19 (63\%) foram realizadas com estudantes do ensino superior; três (10\%) com estudantes do ensino médio; e apenas uma pesquisa (3\%) com estudantes de MBA. Do restante, quatro pesquisas estudaram a $\mathrm{AEC}$ em professores universitários (13\%) e quatro avaliaram trabalhadores de ocupações variadas (13\%).

Contabilizando os países onde as pesquisas foram realizadas, constatou-se um predomínio de estudos realizados nos Estados Unidos, correspondendo a 17 pesquisas (56\%). Inglaterra, Romênia, Tailândia e Taiwan apresentaram duas pesquisas cada um, e outros países como Austrália, China, Escócia, Espanha, Líbano e Malásia apresentaram apenas uma pesquisa cada um.

Sobre as escalas psicométricas adotadas nos artigos mencionados, observa-se o predomínio da aplicação da escala desenvolvida por Murphy et al. (1989) que avalia a autoeficácia específica no uso de computadores. A escala, aplicada em sua versão original ou em versões adaptadas, foi utilizada em nove artigos (30\%). A escala de Torkzadeh et al. (1999), adaptada da versão original de Murphy et al. (1989), foi adotada em quatro publicações (13\%). Os artigos que utilizaram a escala de Muphy et al. (1989) apresentaram evidências de validade da escala, por meio de técnicas como análise fatorial exploratória (Torkzadeh et al.1999 e Barbeite \& Weiss, 2004), análise fatorial confirmatória - LISREL (Torkzadeh et al., 2003) e análise da variância (Chou \& Wang, 2000). Para maiores detalhes, ver Tabela 1.

A escala de avaliação da AEC de Compeau e Higgins (1995), que estima a autoeficácia geral, teve participação relevante nos artigos apresentados, aparecendo em 7 produções ( $23 \%$ das referências citadas). Foram encontradas evidências de validade dessa medida por meio de análises fatoriais confirmatórias (Hsu et al., 2009 e Tzeng, 2009). Agarwal et al. (2000) e Ng (2006) também encontraram evidências de validade da escala de Compeau e Higgins (1995) por meio de equações estruturais (ver Tabela 1).

As escalas de Gist, Schwoerer e Rosen (1989), Kinzie, Delcourt e Powers (1994) e de Cassidy e Eachus (2002) foram referidas pelos autores de quatro artigos, mas não foram encontradas análises que demonstrassem evidências de validade dessas escalas. Foram relatadas apenas análises descritivas ou correlacionais de dados.

As escalas de Beas, Agut, Salanova e Grau (1999), Hsu et al. (2009) e Duncan e McKeachie (2005) foram adotadas nos estudos de Salanova, Grau, Cifre e Llorens (2000), Hsu et al. (2009) e Tzeng (2009), respectivamente. Foram encontradas evidências de validade apenas das escalas de Hsu et al. (2009) e Duncan e McKeachie (2005) por meio de técnicas de análises fatoriais confirmatórias (ver Tabela 1).

A análise dos artigos forneceu respostas a algumas questões norteadoras desta revisão. Observou-se que a teoria de Bandura (1986) é o referencial teórico predominante nas pesquisas. Entretanto, as definições dos construtos subjacentes à construção das escalas de AEC não abrangem todas as três dimensões de autoeficácia propostas pelo autor. Além disso, a análise dos artigos mostrou que as pesquisas sobre esse assunto foram predominantemente realizadas em contextos de ensino superior, com amostras de estudantes universitários. Em função disso, a generalização desses resultados para outros contextos, como o de treinamento corporativo, devem ser feitos com cautela.

A análise dos artigos demonstrou ainda que o conceito de AEC adotado pelos autores na construção de medidas baseou-se na definição de uma única dimensão, denominada "força", desconsiderando as demais, denominadas "magnitude" e "generalização", de acordo com a abordagem teórica de Bandura (1986). Assim, na amostra de artigos pesquisada, a AEC não foi avaliada como construto tridimensional, o que indica a necessidade de aprimoramento das definições e instrumentos de AEC em pesquisas futuras. 


\section{Principais resultados das pesquisas sobre AEC}

As análises apresentadas pelos 30 trabalhos revisados apontam, em seis deles (20\%), índices que confirmam a correlação entre autoeficácia no uso de computadores e conhecimentos anteriores sobre informática, experiência prévia ou frequência de uso pessoal do computador anterior à avaliação do sujeito (Barbeite \& Weiss, 2004; Kagima \& Hausafus, 2000; Karsten \& Roth, 1998; Potosky, 2002; Salanova et al., 2000; Torkzadeh et al., 1999). A frequência de participação dos sujeitos da amostra em treinamentos introdutórios ou cursos breves sobre novas tecnologias de informação e comunicação (NTICs) também se confirmou positivamente correlacionada com a AEC em três artigos da revisão (Agarwal et al., 2000; Brinkerhoff, 2006; Salanova et, al. 2000).

Atitudes positivas perante o uso do computador, baixa ansiedade, confiança no uso da máquina, propensão para utilizar mais computadores e laboratórios de informática ou mais acessos ao software de apoio à aprendizagem também se confirmaram como aspectos correlacionados como nível de AEC dos indivíduos (Agarwal et al., 2000; Hasan, 2006; Ismail, Mahmud, Nor, Ahmad \& Rahman, 2011; Khorrami-Arani, 2001; Mcilroy, Sadler \& Boojawon, 2007; Noiwan, Piyawat, \& Norcio, 2005; Tams, Craig \& Murphy, 2011; Torkzadeh et al., 2006; Torkzadeh et al., 1999). Nas correlações negativas entre a autoeficácia e outras variáveis foi encontrado, no artigo de Agarwal et al. (2000), que o nível de estresse associado ao uso da internet apresentou-se negativamente correlacionado com o nível de autoeficácia no uso da internet dos respondentes.

As diferenças de gênero também se destacaram nos artigos pesquisados. Entre os 30 artigos citados, três (10\%) encontraram evidências de que homens, em algumas situações, apresentaram maiores níveis de AEC do que as mulheres (Chou \& Wang, 2000; Durndell \& Haag, 2002; Eastin \& LaRose, 2000; Kagima \& Hausafus, 2000).

Ao analisar os artigos desta revisão, nota-se que o construto autoeficácia no uso do computador foi estudado tanto como variável independente como variável dependente. Como variável critério, os pesquisadores Barbeite e Weiss (2004) confirmaram a autoeficácia no uso de computadores como fator antecedente à percepção de conforto no uso de computadores. Com resultado parecido, Hasan (2006) investigou o modelo TAM (Technology Acceptance Model - Modelo de Aceitação de Tecnologia) proposto por Davis, Bagozzi e Warshaw (1989), e concluiu que a AEC pode ser considerada variável antecedente à percepção do aprendiz sobre a facilidade no uso de computadores, influenciando-a de maneira positiva.

A AEC específica confirmou-se como variável antecedente à percepção de facilidade no uso de computadores e à intenção de seu uso pelo aprendiz. Em uma pesquisa que também utilizou o modelo TAM como referência, Ismail et al. (2011) concluíram, por meio de um estudo com professores, que a AEC está positivamente correlacionada à percepção de facilidade de utilização e de utilidade de uma livraria virtual de conteúdos didático-pedagógicos que informam sobre técnicas importantes para uso em sala de aula.

Como variável critério, Karsten e Roth (1998) encontraram que universitários que estão mais próximos da data de formatura apresentaram níveis mais elevados de percepção de autoeficácia no uso do computador. A experiência prévia e a participação anterior em um curso de informática também se comportaram como variáveis positivamente correlacionadas com o nível de AEC percebido pelo respondente (Brinkerhoff, 2006; Chou \& Wang, 2000; Mcilroy, Sadler, \& Boojawon, 2007).

No Brasil, Alvarenga (2011) estudou o nível de autoeficácia no uso de computadores de professores na utilização de tecnologias de informática no ensino. Participaram do estudo 253 professores de escolas públicas do município de Campinas-SP. Aos participantes, foi aplicado um questionário que investigou a percepção de autoeficácia computacional docente e suas fontes. Os resultados apontaram que os professores apresentaram, em geral, uma crença de autoeficácia computacional moderada. A experiência vicária foi a fonte mais percebida como constituinte da sua crença de autoeficácia para usar tecnologias no ensino, seguida da persuasão social e da experiência direta. Ao final, a autora propôs que professores com crenças mais elevadas de AEC são os que acreditam ter melhor habilidades para usar o computador e que se sentem mais preparados e motivados para ensinar com tecnologias.

A revisão sobre AEC demonstrou que esse é um construto que tem sido investigado na avaliação de programas educacionais e de treinamento corporativo, em amostras de trabalhadores (Colquitt et al., 2000; Frayne 
\& Geringer, 2000; Lorenz et al., 2000; Meneses \& Abbad, 2003; Ng, 2006; Salanova et al., 2000; Potosky, 2002), estudantes do ensino médio (Eastin \& LaRose, 2000; Khorrami-Arani, 2001; Tzeng 2009), estudantes universitários (Noiwan et al., 2005; Burkhard \& Roldan, 2009 e Tams et al., 2011) e estudantes de MBA (Hsu et al., 2009).

Além dos estudos que analisaram especificamente o tema autoeficácia no uso de computadores, também foram considerados artigos que associaram a autoeficácia geral com a área de treinamento e aprendizagem. Entre eles, destacam-se quatro, considerados representativos desse tipo de contexto: Colquitt et al. (2000), Frayne e Geringer, (2000), Lorenz et al. (2000) e Meneses e Abbad (2003).

Colquitt et al. (2000) propuseram uma metanálise e um modelo de investigação sobre motivação para aprender e transferir novas aprendizagens para o trabalho, seus antecedentes e suas relações com os resultados de treinamento. Os autores concluíram que características individuais, entre elas a autoeficácia, estão direta e positivamente relacionadas com motivação para o treinamento, que, por sua vez, exerce influência direta e positiva sobre a transferência de treinamento para o trabalho.

Frayne e Geringer (2000) confirmaram a relação entre autoeficácia e impacto do treinamento no trabalho de egressos de treinamentos por meio de uma pesquisa de campo realizada junto a participantes de um curso de formação para 30 vendedores, no qual foram adotadas técnicas de autogestão, como palestras, grupos de discussões e estudos de caso. Os resultados mostraram que os participantes do treinamento que apresentaram, durante o evento, alta percepção de autoeficácia e maior expectativa de alcance de metas de trabalho objetivas, revelaram uma melhoria expressiva no desempenho no trabalho, em atividades que requeriam a expressão das competências desenvolvidas pelo treinamento. Essa melhoria no desempenho dos egressos do curso foi duradoura, pois foi observada por mais de 12 meses após o treinamento.

Lorenz et al. (2000) corroboraram as ideias de Goldstein (1991) e asseguraram que, por meio de sua pesquisa com profissionais da área da saúde, o nível de autoeficácia dos egressos de treinamento mostrou-se direta e positivamente correlacionado com a percepção de aplicação eficaz das novas competências ensinadas pelo evento instrucional após o curso.

No Brasil, Meneses e Abbad (2003) apresentaram um estudo que investigou a relação entre as características de treinamentos e suas clientelas, suporte à transferência e impacto do treinamento no trabalho em três organizações brasileiras. Nesse estudo, a variabilidade da auto e heteroavaliação do impacto do treinamento no trabalho dos egressos foi explicada pelas seguintes variáveis: percepção de autoeficácia, suporte psicossocial percebido pelos participantes, suporte psicossocial percebido pelas chefias e colegas de trabalho e quantidade de instrutores por turma. Conforme os autores, entre as variáveis relacionadas às características da clientela, a percepção de autoeficácia do participante foi a única que explicou uma porção significativa das respostas sobre o impacto do treinamento no trabalho, mostrando-se positivamente correlacionada com a aplicação de novas aprendizagens no trabalho.

Os achados científicos relatados nesta revisão apontam para a relevância de ampliar a busca de pesquisas realizadas no Brasil e, especialmente, em situações de treinamento que utilizam o computador e outras tecnologias como importante ferramenta de apoio à aprendizagem.

\section{DISCUSSÃO}

A análise da amostra de artigos sobre autoeficácia no uso de computadores (AEC) forneceu respostas às seis questões indutoras deste trabalho de revisão de literatura. Sobre a primeira questão, "(1) Há algum referencial teórico predominante nas pesquisas sobre AEC?”, foi observado que as pesquisas analisadas possuem a teoria de autoeficácia de Bandura (1986) como referencial dominante; adotam instrumentos de medida focados apenas na dimensão de autoeficácia denominada força; e constituem-se em surveys, aplicados em amostras de estudantes predominantemente universitários.

Outro ponto importante encontrado relaciona-se à segunda questão: "(2) Quais são as definições adotadas na construção de escalas de AEC?”. Os dados demonstraram que o conceito de AEC adotado pelos autores na construção de medidas baseou-se na definição de uma única dimensão, denominada "força", desconsiderando as demais, denominadas "magnitude" e "generalização", de acordo com a abordagem teórica de Bandura (1986). Conclui-se que na amostra de artigos pesquisada, a AEC não foi avaliada como construto tridimensional, o que indica a necessidade de aprimoramento das definições e instrumentos de AEC em pesquisas futuras. Esse 
resultado também responde à questão “(4) Em que se assemelham as escalas de medida adotadas nos estudos?”, uma vez que a dimensão "força", relacionada ao nível de confiança (ou conviçção) apresentado pelo indivíduo sobre a própria capacidade de usar o computador, teve destaque nos estudos consultados. Ainda, observou-se que as escalas construídas originalmente por Murphy et al. (1989) - que avalia autoeficácia específica no uso de computadores - e por Compeau e Higgins (1995) - que avalia autoeficácia geral no uso do computador - foram as mais adotadas pelos artigos.

Respondendo à questão "(3) Quais contextos de pesquisa (educacionais ou de treinamento corporativo) e de amostras de participantes são mais estudados?”, constatou-se que estudantes universitários compunham grande parte dos sujeitos das pesquisas, as quais foram, em sua maioria, realizadas nesse contexto de ensino e educação superior.

A resposta à questão "(5) Os principais achados das pesquisas mostram quais relações (positivas diretas ou indiretas) de AEC com quais resultados de aprendizagem?” demonstra que os resultados apresentados evidenciaram relações positivas entre a AEC e o desempenho de aprendizes durante e após o curso ou treinamento, no que se refere à aprendizagem, à transferência e à aplicação de novos conhecimentos, habilidades e atitudes.

Finalmente, sobre a última questão, “(6) Quais são as principais lacunas nas pesquisas sobre AEC?”, observou-se que os estudos relatados enfocaram apenas a avaliação da dimensão "força" da autoeficácia no uso de computadores, preterindo as dimensões "magnitude" e "generalização". Além dessa lacuna, constatou-se também a necessidade de definir e avaliar melhor as diferenças entre as definições do construto denominado "AEC geral" (conforme apresentado por Compeau \& Higgins, 1995) e "AEC específica" (conforme definido por Murphy et al., 1989). As diferenças entre essas formas de abordagem não foram devidamente debatidas nos trabalhos revisados.

Apesar dos importantes achados identificados nesta revisão, a análise de artigos apresenta limitações, entre elas o uso combinado de poucos termos de busca (computer self-efficacy (CSE), training e learning), o que pode ter levado a uma restrição da amostra final de estudos. Outros termos correlacionados com as palavras-chave (learning), como education, instruction, e-learning, distance education, e "computer", como information and communication technology (ICT) ou virtual environments, se tivessem sido adotados, poderiam ter ampliado a amostra de artigos sobre escalas de avaliação da AEC. Além disso, a revisão não abarca estudos sobre blended learning, tampouco sobre mobile learning, assuntos relativamente pouco pesquisados, mas que tem se mostrado uma tendência para os próximos anos na educação, no treinamento corporativo e na mediação das interações sociais.

Como agenda de pesquisa para os próximos anos no Brasil, propõe-se relacionar o tema AEC com outras variáveis critério de grande interesse como: evasão e persistência em cursos a distância, aprendizagem em cursos mediados pelo computador, internet ou outras NTICs e reações e transferência de aprendizagem. Além disso, é recomendável a realização de pesquisas relacionando ansiedade ou estresse vivenciado por aprendizes no uso do computador em situações de ensino-aprendizagem a atitudes de aceitação ou rejeição de tecnologias no uso de computadores e NTICs.

O modelo TAM proposto por Davis, Bagozzi e Warshaw (1989) parece promissor e pode ser adotado para compreender atitudes e correlacioná-las a percepções de autoeficácia em situações de aprendizagem mediada por computadores. Sugere-se também a construção de novas escalas de AEC e no uso de NTICs, que abordem autoeficácia em atividades de ensino-aprendizagem fundamentadas em tecnologias apoiadas em dispositivos móveis e recursos de interação como os smartphones, tablets e redes sociais. Almejando a elaboração de novas medidas de AEC, que contenham todas os aspectos do conceito, sugere-se a inclusão de itens que mensurem, além da dimensão "força" - comum nas medidas utilizadas nas pesquisas analisadas neste artigo- as demais dimensões da autoeficácia propostas por Bandura (1986) - a magnitude e a generabilidade. Além disso, é preciso analisar e distinguir melhor os construtos de autoeficácia geral no uso do computador (Compeau \& Higgins, 1995) e específica (Gist et al., 1989; Murphy et al., 1989).

Em suma, a crescente necessidade de aprendizado de novas e complexas competências profissionais e o aumento de cursos on-line fez emergir uma necessidade e interesse em pesquisar sobre variáveis individuais, motivacionais, atitudinais, cognitivas, psicossociais e contextuais, que possam favorecer os resultados de aprendizagem e a aplicação de novas e importantes habilidades pessoais e profissionais em diferentes contextos de trabalho e de estudo. A autoeficácia no uso de computadores é uma das variáveis que precisam ser mais estudadas, tanto em contextos educacionais como em situações de treinamento de pessoal em organizações de trabalho, uma vez que está associada a importantes resultados de aprendizagem almejados por instruto- 
res, aprendizes, instituições de ensino e organizações que investem na educação formal e em programas de

Treinamento, Desenvolvimento e Educação (TD\&E) em empresas públicas e privadas.

\section{REFERÊNCIAS}

Agarwal, R., Sambamurthy, V., \& Stair, R. (2000). The evolving relationship between general and specific computer literacy: An empirical assessment. Information Systems Research, 11(4), 418-430.

Alvarenga, C. E. A. (2011). Autoeficácia de professores para utilizarem tecnologias de informática no ensino (Tese de doutorado). Recuperado de http://www.bibliotecadigital.unicamp.br/document/?code=000789633.

Bandura, A. (1986). Social foundations of thought and action: A social cognitive theory. Englewood Cliffs: Prentice-Hall.

Bandura, A. (1994). Self-efficacy. In V. S. Ramachaudran (Ed.), Encyclopedia of human behavior (Vol. 4, pp.71-81). New York: Academic. Encyclopedia of mental health. San Diego: Academic Press. doi: http://dx.doi.org/10.1037/10522-094

Bandura, A. (2005). Evolution of social cognitive theory. In K. G. Smith \& M. A. Hitt (Eds.), Great minds in management (pp. 9-35). Oxford: Oxford University Press.

Barbeite, F. G., \& Weiss, E. M. (2004). Computer self-efficacy and anxiety scales for an Internet sample: Testing measurement equivalence of existing measures and development of new scales. Computers in Human Behavior, 20, 1-15. doi: http:// dx.doi.org/10.1016/S0747-5632(03)00049-9

Beas, M. I., Agut, S., Salanova, M., \& Grau, R. (1999). La autoeficacia general y especıfica y su relacion com diversos indicadores de estres laboral. Trabalho apresentado na IV International Conference on Cognitive/Behavioral Psychology, Valencia, Espanha.

Brinkerhoff, J. (2006). Effects of a Long-Duration, professional development academy on technology skills, computer self-efficacy and technology integration beliefs and practices. Journal of Research on Technology in Education, 39(1), 22-43. doi: http:// dx.doi.org/10.1080/15391523.2006.10782471

Brosnan, M. J. (1998). The impact of computer anxiety and self-efficacy upon performance. Journal of Computer Assisted Learning, 14, 223-234. doi: http://dx.doi.org/10.1046/j.1365-2729.1998.143059.x

Burkhard, R., \& Roldan, M. (2009). Task context and computer self efficacy in the era of web 2.0 tool. Journal of Online Learning and Teaching, 5(1), 155-165.

Cassidy, S., \& Eachus, P. (2002). Developing the computer self-efficacy scale (CUSE): investigating the relationship between computer self-efficacy, gender and experience with computers. Journal of Educational Computer Research, 26, 169-189. doi: http://dx.doi.org/10.2190/JGJR-OKVL-HRF7-GCNV

Chou, H. W., \& Wang, T. B. (2000). The influence of learning style and training method on self-efficacy. International Journal of Information Management, 20, 455-472.

Claggett, J. L., \& Goodhue, L. D. (2011). Have is researchers lost Bandura self-efficacy concept? A Discussion of the Definition and Measurement of Computer Self-Efficacy. Proceedings of the 44th hawaii international conference on system sciences 2011.

Colquitt, J. A., LePine, J. A., \& Noe, R. A. (2000). Toward an integrative theory of training motivation: a meta-analytic path analysis of 20 years of research. Journal of Applied Psychology, 85, 678-707.doi: http://dx.doi.org/10.1037/0021-9010.85.5.678

Compeau, D. R., \& Higgins, C. A. (1995) Computer self-efficacy: Development of a measure and initial test. MIS Quarterly, 19(2), 189-211. doi: http://dx.doi.org/10.2307/249688.

Davis, F. D.; Bagozzi, R. P.; Warshaw, P. R. (1989). User acceptance of computer technology: A comparison of two theoretical models. Management Science, 35, 982-1003. doi: http://dx.doi.org/10.1287/mnsc.35.8.982

Duncan, T. G., \& McKeachie, W. J. (2005). The making of the motivated strategies for learning questionnaire. Educational Psychologist, 4O(2), 117-128.

Durndell, A., \& Haag, Z. (2002). Computer self efficacy, computer anxiety, attitudes towards the Internet and reported experience with the Internet, by gender, in an East European sample. Computers in Human Behavior, 18, 521-535.

Durndell, A., Haag, Z., \& Laithwaite, H. (2000). Computer self-efficacy and gender: A cross cultural study of Scotland and Romani. Personality and individual differences, 28, 1037-1044.

Eastin, M. S., \& LaRose, R. (2000). Internet self-efficacy and the psychology of the digital divide. Journal of Computer Mediated Communication, 6(1). doi: http://dx.doi.org/10.1111/j.1083-6101.2000.tb00110.x

Frayne, C. A., \& Geringer, J. M. (2000). Self-management training for improving job performance: A field experiment involving salespeople. Journal of Applyed Psychology, 85, 361-72. doi: http://dx.doi.org/10.1037//0021-9010.85.3.361 
Gist, M. E. (1987). Self-Efficacy: Implications for organizational behavior and human resource management. The Academy of Management Review, 12, 472-485.

Gist, M. E., Schwoerer, C., \& Rosen, B. (1989). Effects of alternative training methods on self-efficacy and performance in computer software training. Journal of Applied Psychology, 74(6), 884-891. doi: http://dx.doi.org/10.1037/0021-9010.74.6.884

Goldstein, I. L. (1991). Training in work organizations. In M. D. Dunnette \& L.M. Houg (Orgs.), Handbook of industrial and organizational psychology (2a ed., pp. 507-619). Palo Alto: Consulting Psychologists Press.

Hasan, B. (2003). The influence of specific computer experiences on computer self-efficacy beliefs. Computers in Human Behavior, 19, 443-450. doi: http://dx.doi.org/10.1016/S0747-5632(02)00079-1

Hasan, B. (2006). Examining the effects of computer self-efficacy and system complexity on technology acceptance. Information Resource Management Journal, 20(3), 76-88. doi: http://dx.doi.org/10.4018/irmj.2007070106

Hsu, K., Wang, S. W., \& Chiu, K. K. (2009). Computer attitude, statistic anxiety and self-efficacy on statistical software adoption behavior: an empirical study of online MBA learners. Computer in Human Behavior, 25, 412-429. doi: http://dx.doi. org/10.1016/j.chb.2008.10.003

Ismail, M. A., Mahmud, R., Nor, M. N., Ahmad, J., \& Rahman, M. J. A. (2011). Computer self-efficacy: Teacher readiness in accepting Malaysian EduwebTV. World Applied Sciences Journal, 14, 60-66.

Kagima, L., \& Hausafus, C. (2000). Integration of electronic communication in higher education: contributions of faculty computer self-efficacy. The Internet and Higher Education, 2(4), 221-235. doi: http://dx.doi.org/10.1016/S1096-7516(00)00027-0

Karsten, R., \& Roth, M. R. (1998). Computer self-efficacy - A practical indicator of student computer competency in introductory IS courses. Informing Science, 1(3),

Kinzie, M. B., Delcourt, M., \& Powers, S. M. (1994). Computer technologies: Attitudes and self-efficacy across undergraduate disciplines. Research in Higher Education, 35(6), 745-768.

Khorrami-Arani, O. (2001). Researching computer self-efficacy. International Education Journal, 2(4), 17-25.

Kuo, F. Y., \& Hsu, M. H. (2001). Development and validation of Ethical Computer Self-Efficacy Measure: The Case of Softlifting. Journal of Business Ethics, 32, 299-315.

Lorenz, R., Gregory, R. P., \& Davis, D. L. (2000). Utility of a brief self-efficacy scale in clinical training program evaluation. Evaluations \& the Health Professions, 23, 182-193. doi: http://dx.doi.org/10.1177/016327870002300204

Madhavan, P., Rachel, R., \& Phillips, R. R. (2010). Effects of computer self-efficacy and system reliability on user interaction with decision support systems. Computers in Human Behavior, 26, 199-204. doi: http://dx.doi.org/10.1016/j.chb.2009.10.005

Marakas, G. M., Mun, Y. Y., \& Johnson, R. D. (1998). The multilevel and multifaceted character of computer self-efficacy: Toward clarification of the construct and an integrative framework for research. Information Systems Research, 9(2), 126-163. doi: http://dx.doi.org/10.1287/isre.9.2.126

Mcilroy, D., Sadler, C., \& Boojawon, N. (2007). Computer phobia and computer self-efficacy: Their association with undergraduates' use of university computer facilities. Computers in Human Behavior, 23, 1285-1299. doi: http://dx.doi.org/10.1016/j. chb.2004.12.004

Meneses, P. P. M., \& Abbad, G. S. (2003). Preditores individuais e situacionais de auto e heteroavaliação de impacto de treinamento no trabalho. RAC - Revista de Administração Contemporânea, 7, 185-204.

Meneses, P. P. M., \& Abbad, G. S. (2010). Construção e validação de um instrumento para avaliar auto-eficácia em situações de treinamento, desenvolvimento e educação de pessoas. Psicologia: Reflexão e Crítica, 23(1), 141-150. doi: http://dx.doi. org/10.1590/S0102-79722010000100015

Murphy, C., Coover, D., \& Owen, S. (1989). Development and validation of the computer self-efficacy scale. Educational and Psychological Measurement, 49, 893-899. doi: http://dx.doi.org/10.1177/001316448904900412

$\mathrm{Ng}$, Y. C. (2006). Levels of computer self-efficacy, computer use and earnings in China. Economics Letters, 90, 427-432. doi: http://dx.doi.org/10.1016/j.econlet.2005.10.004

Noiwan, J., Piyawat, T., \& Norcio, A. F. (2005). Computer attitude and computer self-efficacy: A case study of thai undergraduate students. Trabalho apresentado na 11th International Conference on Human Computer Interaction, Nevada, EUA.

Papasratorn, B., \& Wangpipatwong, T. (2006). The Effects of Self-efficacy and Attitude on E-learning Outcomes. In T. Reeves \& S. Yamashita (Eds.), Proceedings of World Conference on E-Learning in Corporate, Government, Healthcare, and Higher Education 2006 (pp. 2264-2270). Chesapeake, VA: Association for the Advancement of Computing in Education (AACE). 
Potosky, D. (2002). A field study of computer efficacy beliefs as an outcome of training: The role of computer playfulness, computer knowledge, and performance during training. Computers in Human Behavior, 18, 241-255. doi: http://dx.doi.org/10.1016/ S0747-5632(01)00050-4

Salanova, M., Grau, R., Cifre, E., \& Llorens, S. (2000). Computer training, frequency of usage and burnout: the moderating role of computer self-efficacy. Computers in Human Behavior, 16, 575-590. doi: http://dx.doi.org/10.1016/S0747-5632(00)00028-5

Saleh, H. K. (2008). Computer self-efficacy of university faculty in Lebanon. Education Tech Research Dev, 56, 229-240. doi: http://dx.doi.org/10.1007/s11423-007-9084-z

Santhanam, R., Sasidharan, S., \& Webster, J. (2008). Using Self-Regulatory Learning to Enhance E-Learning-Based IT. Training Information Systems Research, 19(1), 26-47.

Tams, S., Craig, K., \& Murphy, R. (2011). Coping with interruptions in computer-mediated environments: the role of computer selfefficacy. Computer Self-Efficacy as a Coping Mechanism. Proceedings of the Southern Association for Information Systems Conference, Atlanta, USA, 25-26 March 2011. 175-180.

Torkzadeh, G., Chang, J. C., \& Demirhan, D. (2006). A contingency model of computer and Internet self-efficacy. Information \& Management, 43, 541-550. doi: http://dx.doi.org/10.1016/j.im.2006.02.001

Torkzadeh, G. \& Koufteros, X. (1994). Factorial Validity of a Computer Self-Efficacy Scale and the Impact of Computer Training. Educational and Psychological Measurement, 54(3), 813-821. doi: http://dx.doi.org/10.1177/0013164494054003028

Torkzadeh, G., Koufteros, X., \& Pflughoeft, K. (2003). Confirmatory Analysis of Computer Self-Efficacy Structural Equation Modeling: A Multidisciplinary Journal, 10(2), 263-275.

Torkzadeh, G.; Pflughoeft, K., \& Hall, L. (1999). Computer self-efficacy, training effectiveness and user attitudes: an empirical study. Behaviour and Information Technology, 18(4), 299-309. doi: http://dx.doi.org/10.1080/014492999119039

Tzeng, J. Y. (2009). The impact of general and specific performance and self-efficacy on learning with computer-based concept mapping. Computers in Human Behavior, 25, 989-996. doi: http://dx.doi.org/10.1016/j.chb.2009.04.009 